\title{
Knowledge and practice on Toxoplasma infection in pregnant women from Malaysia, Philippines, and Thailand
}

\section{Hemah Andiappan ${ }^{1}$, Veeranoot Nissapatorn ${ }^{1 *}$, Nongyao Sawangjaroen $^{2}$, Si-Lay Khaing ${ }^{3}$, Cristina C. Salibay ${ }^{4}$, Mary Mae M. Cheung ${ }^{5}$, Julieta Z. Dungca ${ }^{6}$, Waenurama Chemoh ${ }^{2}$, Ching Xiao Teng ${ }^{1}$, Yee-Ling Lau ${ }^{1}$ and Noor A. Mat Adenan ${ }^{3}$}

${ }^{1}$ Department of Parasitology, Faculty of Medicine, University of Malaya, Kuala Lumpur, Malaysia

2 Department of Microbiology, Faculty of Science, Prince of Songkla University, Hat Yai, Songkhla, Thailand

${ }^{3}$ Department of Obstetrics and Gynecology, Faculty of Medicine, University of Malaya, Kuala Lumpur, Malaysia

${ }^{4}$ Biological Sciences Department, De La Salle University - Dasmariñas, Cavite, Philippines

${ }^{5}$ College of Arts and Sciences, Notre Dame of Dadiangas University, General Santos, Philippines

${ }^{6}$ School of Science and Technology, Centro Escolar University, Manila, Philippines

\section{Edited by:}

Hervé Pelloux, CHU A. Michallon,

France

Reviewed by:

Ranjit Kumar, University of Birminghm at Alabama, USA

Hridayesh Prakash, University of Hyderabad, India

*Correspondence:

Veeranoot Nissapatorn, Department of Parasitology, Faculty of Medicine,

University of Malaya, 50603 Kuala

Lumpur, Malaysia

e-mail:nissapat@gmail.com
Toxoplasma gondii, is one of the infectious agents of congenital TORCH infections, causes severe clinical outcomes in fetus and newborns. Nevertheless this life-threatening parasitic disease is preventable by simple preventive measures related to lifestyle during pregnancy. We aim to study on the knowledge about toxoplasmosis and practices that prevents this infection among the pregnant women. Total of 2598 pregnant women from Malaysia, Philippines, and Thailand were randomly surveyed to determine the knowledge and their practices on Toxoplasma infection. The questionnaire covered respondents' general information and knowledge on plausible risks factors, symptoms, timing of infection, prevention knowledge, and preventive behavior regarding Toxoplasma infection. Majority of these pregnant women were in their age group of 20-29 years (50.9\%), completed secondary level of education $(51.7 \%)$, in their second trimester of pregnancies $(38.1 \%)$, non-parous (36.6\%), and had no history of abortion $(90.4 \%)$. Based on this survey, only $11 \%$ of these pregnant women had read, heard, or seen information regarding toxoplasmosis and $3.5 \%$ of them were aware of being tested for the infection. A small percentage of these pregnant women knew that $T$. gondii were shed in the feces of infected cats $(19.4 \%)$ and sometimes found in the raw or undercooked meat $(11.0 \%)$. There was $16.1 \%$ of responding women knew that toxoplasmosis is caused by an infection. Demographic profiles such as age group, level of education, pregnancy term, and number of children of the pregnant women showed significant association with their responses toward prevention knowledge and preventive behavior related questions $(P<$ 0.05). Thus, it is suggested that health education on toxoplasmosis and primary behavioral practices should be consistently offered to reproductive age women in general and pregnant women in particular. This information could help to reduce vertical transmission of Toxoplasma infection during pregnancy.

Keywords: toxoplasmosis, knowledge, practice, pregnant women, Malaysia, Philippines, Thailand

\section{INTRODUCTION}

Toxoplasma gondii, an obligate intracellular coccidian protozoan, is the causative agent of Toxoplasmosis. Toxoplasma have three main forms in its entire life cycle, being; oocysts, tachyzoites, and bradyzoites. The definitive host of Toxoplasma is the felines, where oocysts are produced in the intestines and passed in feces. The oocyst is infective to humans and other intermediate host (mammals and other warm blooded animals). Once infected, Toxoplasma develops itself into tachyzoites (rapid multiplication of Toxoplasma in trophozoite form) or maintain dormant in bradyzoites (tissue cysts), depending on the host immune status (John and Petri, 2006). The infection in pregnant women may cause devastating effects in the fetus. If the infected tissue of an animal being consumed, it acts as a transmission mode of infection. Furthermore, this parasitic infection can be transmitted by ingestion of Toxoplasma oocysts contaminated fruits and vegetables or unclean water, through blood transfusion, and by receiving organ transplant (Pereira et al., 2010). Exposures to contaminated feces by cleaning cat's litter, gardening, or handling contaminated soils are some of the ways of this parasitic infection being transmitted.

Most countries in South America, Middle Eastern and other low-income countries reported high seropositive for Toxoplasma infection from both normal or immunocompromised host, e.g., 59\% in Brazil (Ferezin et al., 2013), 84.7\% in Congo (Doudou et al., 2014), 3.98\% in China (Hua et al., 2013), 83.6\% in Ethiopia 
(Zemene et al., 2012), 75\% in India (Chintapalli and Padmaja, 2013), 10.3\% in Japan (Sakikawa et al., 2012), 11.8\% in Taiwan (Chou et al., 2011) and 30.9\% in Tanzania (Mwambe et al., 2013). Meanwhile, the recent seroprevalence rate of Toxoplasma infection in pregnant women was reported as $49 \%$ in Malaysia (Nissapatorn et al., 2003), 23.8\% in the Philippines (Salibay et al., 2008) and $28.3 \%$ in Thailand (Nissapatorn et al., 2011).

Toxoplasma infection in immunocompetent persons is usually asymptomatic (Halonen and Weiss, 2013) however; infection in the immunodeficient patients and in fetus through their pregnant mother may lead up to severe and often fatal toxoplasmosis. The clinical signs in infected fetus will be intracranial calcifications, hydrocephalus, eye infection, seizures, miscarriage, or death (Paquet and Yudin, 2013). The annual incidence of congenital toxoplasmosis was estimated at 190,100 cases globally (Torgerson and Mastroiacovo, 2013). The clinical presentation was not or rarely shown in infected pregnant women, even during acute infection. Some of the pregnant women may present symptoms like malaise, low-grade fever and lymphadenopathy (Montoya and Remington, 2008). Anti-parasitic antibiotic therapy is the currently available treatment for Toxoplasma infected pregnant women (Paquet and Yudin, 2013). The pregnant women were given spiramycin antibiotic if the infection occurs during the first 18 weeks of gestation, meanwhile pyrimethamine, sulfadiazine and folic acid were given to pregnant women who acquired this parasitic infection after 18 weeks of gestation and onwards (Montoya and Remington, 2008). In the meantime, developments of vaccines are still being studied (Verma and Khanna, 2013).

As toxoplasmosis being one of the TORCH [acronym for a group of five infectious disease namely; Toxoplasmosis, Others (Hepatitis B), Rubella (German measles), Cytomegalovirus (CMV), Herpes Simplex Virus (HSV)] infectious agents in pregnant women, knowledge and practice regarding this disease, and preventive measures in lifestyle for this parasitic infection should be given to the pregnant women. To the best of our knowledge, questionnaire base study on toxoplasmosis has never been conducted in pregnant women from this part of the world. Therefore, this survey aimed to evaluate the level of knowledge and practices on toxoplasmosis among pregnant women who visiting the antenatal clinics (ANC) or hospitals from their respective countries namely Malaysia, Philippines, and Thailand. Southeast Asia is a region where its people share their similarities in term of geographical location, tradition, and culture in their ways of life. This study would definitely provide the new insight on toxoplasmosis in pregnant women.

\section{MATERIALS AND METHODS}

This survey was carried out from January, 2012 to June, 2013 among 3 neighboring countries namely Malaysia, Philippines, and Thailand in Southeast Asia. A total of 2598 being 756 pregnant women visiting ANC at the Department of Obstetrics and Gynecology, University of Malaya Medical Centre, Kuala Lumpur, Malaysia, 1063 pregnant women visiting ANC at the general hospitals and in private clinics and lying-in/maternity hospitals in Luzon and Mindanao, the Philippines and 779 pregnant women visiting ANC at the Songklanagarind and
Hatyai hospital, Songkhla province and Pattani hospital, Pattini province, Thailand were recruited (Figure 1). Inclusion criteria are pregnant women in any gestational periods, in any age groups and given verbal consent to participate in this study.

Demographic information and questions related to general knowledge about toxoplasmosis, risks factors, symptoms, and timing of infection, prevention knowledge, and preventive behavior was adopted from a previous study (Jones et al., 2003) with some modifications. Prior to answering questionnaires, these pregnant women were briefed about toxoplasmosis in term of the definition, risk factors, clinical features, preventive measures by medical practitioners and professional nurses. All data collected were entered and analyzed using SPSS version 17 (IL, Chicago, USA). Data with qualitative variables were expressed as frequency and percentage. Statistical analysis was performed using chisquare test as appropriate. A $P$-value of $<0.05$ was regarded as statistically significant.

\section{RESULTS}

A total of 2598 pregnant women participated in this survey with 756, 1063, and 779 from Malaysia, Philippines and Thailand, respectively. Majority of Malaysian pregnant women were in age group of 20-29 years, married, graduates, in their third trimester, expecting their first born, and had no history of abortion. Filipino pregnant women were mostly in age group of 20-29 years, married, were in secondary school leavers, in their second trimester, having = two children, and had no history of abortion. Meanwhile, Thai pregnant women were mostly in age group of 20-29 years, married, had tertiary level of education, in second trimester, have no children earlier, and had no history of abortion as shown in Table 1.

In general, only $11 \%$ of these pregnant women had read, heard, or seen any information regarding toxoplasmosis and $3.5 \%$ of them were aware of being tested for the infection. A small percentage of these pregnant women knew that Toxoplasma were shed in the feces of infected cats $(19.4 \%)$ and sometimes found in the raw or undercooked meat (11.0\%). There was $16.1 \%$ of responding women knew that toxoplasmosis is caused by an infection, but $4.9 \%$ thought that it is caused by poison. Moreover, there was a low level of knowledge $(<10 \%)$ about other risk factors such as consumption of undercooked meat, drinking untreated water and receiving blood transfusion. A high percentage of pregnant women indicated they do not eat undercooked meat and that they practice good hygienic measures such as washing their hands after handling raw meat, gardening, or changing cat litter as shown in Table 2.

Table 3 shows the association between demographic profiles of pregnant women from each country with their preventive knowledge and preventive behavior on toxoplasmosis (Raw data can be found in Tables 3A,F from Supplement 1). Malaysian pregnant women in the age group of $>40$ years significantly avoiding stray cats; who had tertiary education significant association with their responses in feeding their cat with dry or commercial food, avoiding stray cats, let someone else changing cat litter box daily, wash cooking utensils after each use, washing hands after gardening, changing cat litter and handling raw meat while who educated from primary education significantly reported to wash their hand 


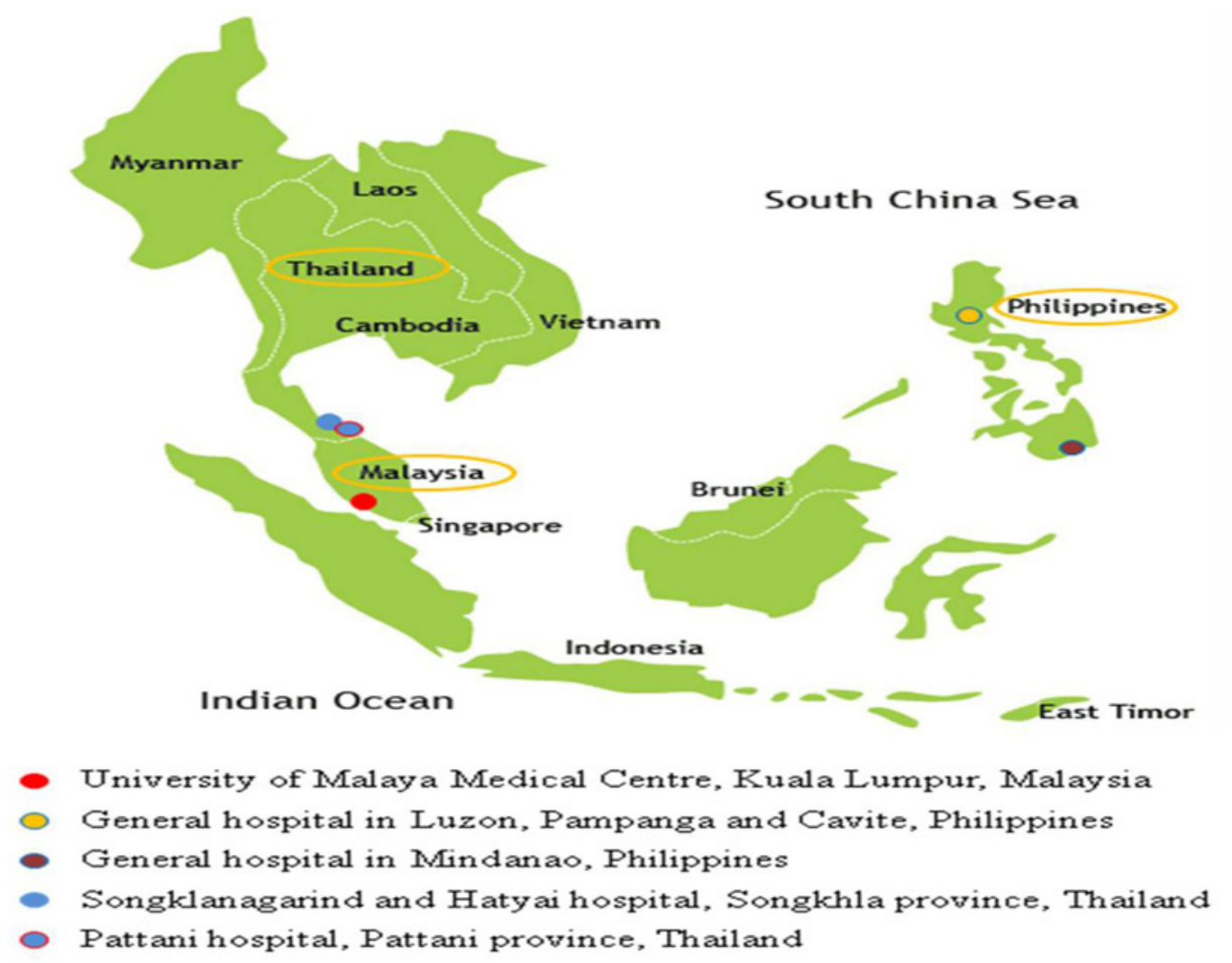


Table 1 | Demographic profiles of the pregnant women.

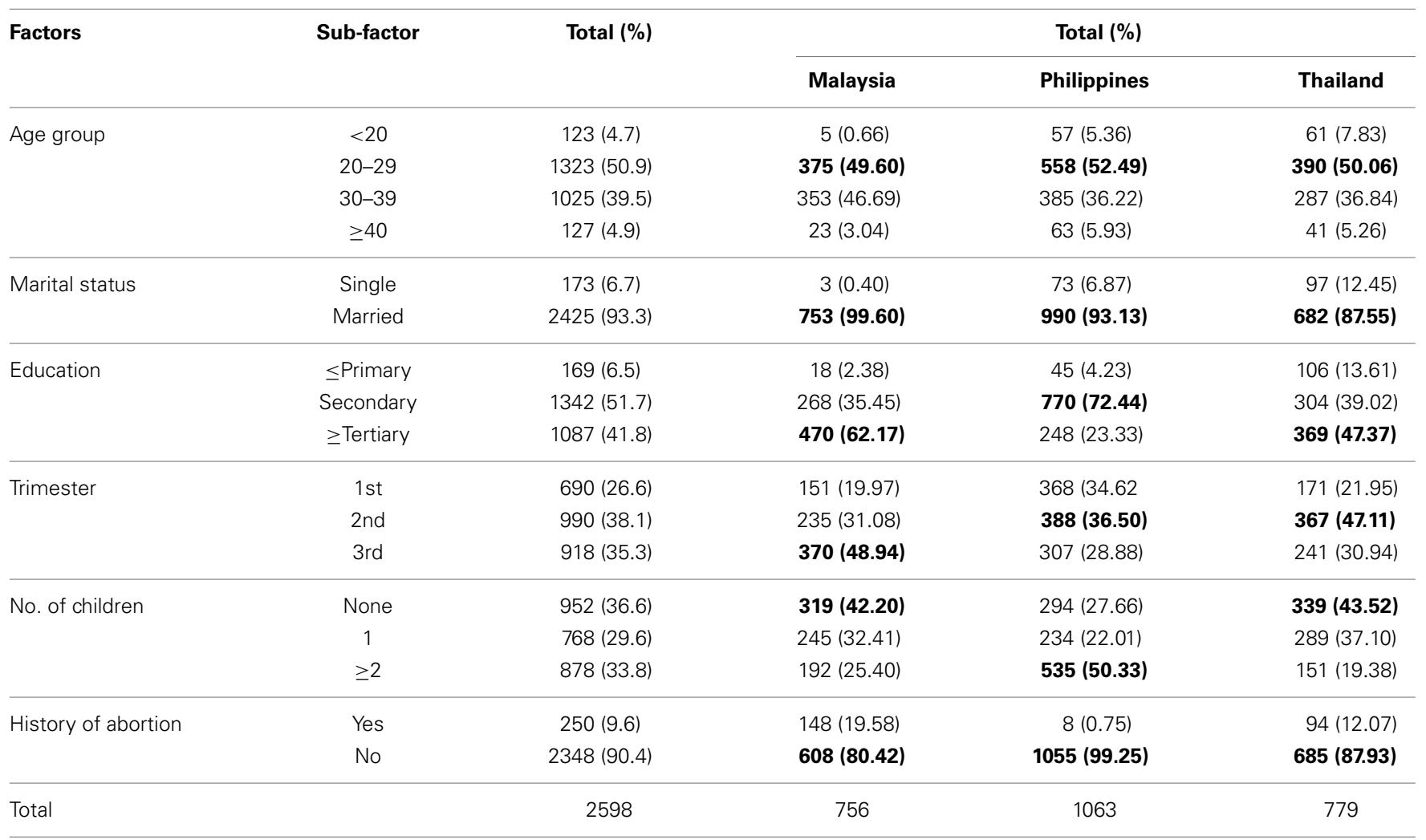

The bold values indicate the highest number of pregnant women for each category from Malaysia, Philippines and Thailand, respectively.

meat. Toxoplasma gondii poses a public health problem for both infection rate and disease burden that have been reported in pregnant women from different parts of the world. This parasite has been found in any given environment conditions that contaminating with cat's feces. Approximately 1.2 million metric tons of cat feces were being deposited in the environment annually with the oocysts burden measured in a community survey was 3 to 434 oocysts per square foot in USA (Torrey and Yolken, 2013) and there have been reports showing that having a close contact with cats and cleaning their litter may transmit the disease to pregnant women (Fakhfakh et al., 2013). Exposure to infected cats by these women could lead to severe outcomes to her carried fetus. Many studies reported Toxoplasma infection in animals for human consumption (Bangoura et al., 2013; Hill and Dubey, 2013; Kang et al., 2013; Lopes et al., 2013), 12.2\% of pregnant women who consume raw meat especially Malaysian who were graduate from primary school and Thai's who were in age group 20-29, single, graduate from tertiary education and in their first semester of pregnancy could be at risk for Toxoplasma infection.

Further analysis revealed that there were some significant association found between the demographic profiles and the responses from these pregnant women regarding their prevention knowledge and preventive behavior. Many of these pregnant women $(>30 \%)$ know that by avoiding stray cats, allowing someone else to change the cat's litter box, making sure the cat's litter box is changed daily, cleaning cooking utensil after each use are preventive measures of toxoplasmosis. Most of them $(>80 \%)$ routinely wash their hand after gardening, changing cat litter and after handling raw meat indicated their constantly practice basic personal hygiene during their pregnancy. Looking at pregnant women in the Philippines, it was found no significant association between demographic profiles and their knowledge on toxoplasmosis, except for their level of education and the number of children. Overall, level of education, marital status, trimester of pregnancy and the number of children play an important role in preventing Toxoplasma infection found in these pregnant women. History of abortion did not have any significant association except in Thai pregnant women who were changing cat's litter box daily.

This study highlights the level of knowledge and practice on awareness of Toxoplasma infection among the pregnant women from three Southeast Asian countries: Malaysia, Philippines, and Thailand. The findings of this study provide vital information in better understanding about the knowledge and practice of toxoplasmosis among pregnant women in this region. Therefore, it emphasizes the need for implementation of health education among this target group to further educate them on the preventive and control measures. We strongly believe that with adequate knowledge and awareness through health education on toxoplasmosis will remarkably eliminate the infection rate and subsequently eradicate its disease burden in these countries. The obtained data also coincide with the actual situation that the incidence of primary acute toxoplasmosis is very low and also clinical evidence of congenital toxoplasmosis is rarely 
Table 2 | Pregnant women responses for knowledge and practice on Toxoplasmosis by country.

\begin{tabular}{|c|c|c|c|c|c|c|c|c|c|c|c|c|c|}
\hline & & \multicolumn{3}{|c|}{$\begin{array}{l}\text { Malaysia (n, \%) } \\
\quad(N=756)\end{array}$} & \multicolumn{3}{|c|}{$\begin{array}{l}\text { Philippines (n, \%) } \\
\quad(N=1063)\end{array}$} & \multicolumn{3}{|c|}{$\begin{array}{l}\text { Thailand (n, \%) } \\
\qquad(N=779)\end{array}$} & \multicolumn{3}{|c|}{$\begin{array}{l}\text { Total }(n, \%) \\
(N=2598)\end{array}$} \\
\hline & & Yes & No & Not sure & Yes & No & Not sure & Yes & No & Not sure & Yes & No & Not sure \\
\hline \multirow{4}{*}{ 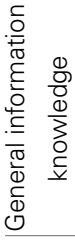 } & K1 & 161 & 519 & 76 & 41 & 964 & 58 & 83 & 340 & 356 & 285 (10.9) & $1823(70.2)$ & 490 (18.9) \\
\hline & K2 & 14 & 706 & 36 & 49 & 979 & 35 & 27 & 396 & 356 & $90(3.5)$ & $2081(80.1)$ & 427 (16.4) \\
\hline & K3 & 206 & 195 & 355 & 176 & 759 & 128 & 36 & 144 & 599 & $418(16.1)$ & 1098 (42.3) & $1082(41.6)$ \\
\hline & K6 & 74 & 182 & 500 & 156 & 682 & 225 & 57 & 84 & 638 & $287(11.0)$ & $948(36.5)$ & $1363(52.5)$ \\
\hline \multirow{4}{*}{$\begin{array}{l}\frac{\omega}{0} \\
\frac{0}{0} \\
\frac{\pi}{\sigma} \\
\frac{v}{0} \\
\frac{\omega}{\sim}\end{array}$} & $\mathrm{R} 1$ & 367 & 81 & 308 & 104 & 584 & 375 & 65 & 46 & 668 & $536(20.6)$ & $711(27.4)$ & $1351(52.0)$ \\
\hline & $\mathrm{R} 2$ & 95 & 166 & 495 & 87 & 658 & 318 & 63 & 53 & 663 & $245(9.4)$ & 877 (33.8) & 1476 (56.8) \\
\hline & R3 & 59 & 210 & 487 & 42 & 654 & 367 & 23 & 91 & 665 & $124(4.8)$ & 955 (36.8) & $1519(58.5)$ \\
\hline & $\mathrm{R} 4$ & 115 & 188 & 453 & 41 & 668 & 354 & 25 & 80 & 674 & 181 (6.9) & $936(36.0)$ & $1481(57.0)$ \\
\hline . & S3 & 168 & 58 & 530 & 36 & 589 & 438 & 48 & 53 & 678 & $252(9.7)$ & 700 (26.9) & $1646(63.4)$ \\
\hline$\stackrel{E}{\stackrel{E}{I}} \simeq$ & S4 & 83 & 68 & 605 & 8 & 683 & 372 & 37 & 54 & 688 & $128(4.9)$ & 805 (30.9) & $1665(64.1)$ \\
\hline 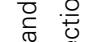 & S5 & 75 & 192 & 489 & 1 & 618 & 444 & 27 & 74 & 678 & $103(4.0)$ & $884(34.0)$ & 1611 (62.0) \\
\hline$\stackrel{\infty}{\infty} \stackrel{\Phi}{\leftrightarrows}$ & S6 & 143 & 113 & 500 & 32 & 649 & 382 & 54 & 53 & 672 & $229(8.8)$ & 815 (31.4) & $1554(59.8)$ \\
\hline 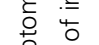 & S7 & 53 & 132 & 571 & 0 & 621 & 442 & 26 & 75 & 678 & $79(3.0)$ & 828 (31.9) & 1691 (65.0) \\
\hline है & S8 & 96 & 72 & 588 & 52 & 648 & 363 & 28 & 58 & 693 & $176(6.7)$ & 778 (29.9) & 1644 (63.3) \\
\hline & s9 & 104 & 62 & 590 & 84 & 620 & 359 & 25 & 65 & 689 & $213(8.2)$ & 747 (28.8) & $1638(63.0)$ \\
\hline & $\mathrm{S} 10$ & 148 & 59 & 549 & 212 & 548 & 303 & 39 & 51 & 689 & 399 (15.4) & $658(25.3)$ & 1541 (59.3) \\
\hline \multirow{3}{*}{ 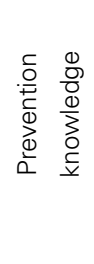 } & $\mathrm{P} 1$ & 281 & 96 & 379 & 179 & 585 & 299 & 264 & 109 & 406 & 724 (27.9) & $790(30.4)$ & $1084(41.7)$ \\
\hline & P2 & 454 & 63 & 239 & 192 & 592 & 279 & 319 & 86 & 374 & $965(37.1)$ & 741 (28.5) & 892 (34.3) \\
\hline & P3 & 458 & 72 & 226 & 174 & 611 & 278 & 242 & 111 & 426 & $874(33.6)$ & $794(30.6)$ & $930(35.8)$ \\
\hline d & B4 & 32 & 0 & 724 & 1024 & 25 & 14 & 562 & 76 & 141 & $1618(62.3)$ & $101(3.9)$ & 879 (33.8) \\
\hline & B5 & 68 & 645 & 43 & 155 & 899 & 9 & 94 & 535 & 150 & 317 (12.2) & $2079(80.0)$ & $202(7.8)$ \\
\hline
\end{tabular}

K1 to K6 are the knowledge on general information of toxoplasmosis. K1: Have you ever read, heard, or seen any information about toxoplasmosis. K2: Have you ever been tested for toxoplasmosis? K3: Is toxoplasmosis caused by an infection? K4: Is toxoplasmosis caused by a poison? K5: Is toxoplasmosis (T.gondii) shed in the feces of infected cats? K6: Is toxoplasmosis (T.gondii) sometimes found in raw or undercooked meat? R1 to R5 are the knowledge on risk factors of toxoplasmosis. R1: Can people get toxoplasmosis by changing cat litter? R2: Can people get toxoplasmosis by eating undercooked meat? R3: Can people get toxoplasmosis by receiving blood transfusion? R4: Can people get toxoplasmosis by drinking untreated water, e.g., rain, tap, or unboiled? R5: Can people get toxoplasmosis by gardening without gloves? S1 to S10 are the knowledge on symptoms and timing of infection of toxoplasmosis. S1: Can pregnant women develop serious complications after infection with toxoplasmosis (T.gondii)? S2: Can unborn and/or newborn children develop serious complications after infection with toxoplasmosis (T.gondii)? S3: Can toxoplasmosis in a pregnant women cause fever and feeling like you have the flu? S4: Can toxoplasmosis in a pregnant women cause swollen glands (lymph node)? S5: Can toxoplasmosis in a pregnant women cause no symptoms? S6: Toxoplasmosis (T.gondii) can only be passed from a pregnant woman to her fetus if she is newly infected during that pregnancy. S7: Toxoplasmosis (T.gondii) is rarely passed from a pregnant woman to her fetus if she is newly infected during that pregnancy. S8: A baby with toxoplasmosis may have no signs of illness at birth, but develop illness later. S9: A baby with toxoplasmosis may have vision problems. S10: A baby with toxoplasmosis may be treated with medicine. $P 1$ to $P 7$ are the preventive knowledge on ways to avoid toxoplasmosis. P1: Feeding your cat dry or commercial cat food and not letting it kill and eat rodents. P2: Avoiding stray cats. P3: Letting someone else change the cat's litter box. P4: Making sure the cat's litter box is changed daily. P5: Toxoplasmosis can be prevented by cooking meat well until no pink is seen and the juices run clear. P6: Toxoplasmosis can be prevented by thoroughly washing and/or peeling all fruits and vegetables before eating them. P7: Toxoplasmosis can be prevented by cleaning all cutting boards and utensils thoroughly after each use. B1 to B5 denotes the preventive behaviors of the pregnant women since becoming pregnant. B1: Do you routinely wash your hands after gardening? B2: Do you routinely wash your hands after changing cat litter? B3: Do you routinely wash your hands after handling raw meat? B4: Do you routinely wash your hands before eating food? B5: Do you eat raw meat?

The bold values indicate the total number of pregnant women who answered "Yes" for each questions in the questionnaire. 
Table 3 | Association between demographic profiles of pregnant women from each country with their preventive knowledge and preventive behavior on Toxoplasmosis.

\begin{tabular}{|c|c|c|c|c|c|c|c|c|c|c|c|c|c|}
\hline & Factors & P1 & $\mathbf{P 2}$ & P3 & P4 & P5 & P6 & P7 & B1 & B2 & B3 & B4 & B5 \\
\hline \multirow{6}{*}{$\frac{\frac{\pi}{\sqrt{n}}}{\frac{\pi}{\pi}}$} & Age group & & $*$ & & & & & & & & & & \\
\hline & Marital status & & & & & & & & & & & & \\
\hline & Education & $*$ & $* *$ & $* *$ & $* *$ & & & $*$ & $*$ & $*$ & & $* *$ & \\
\hline & Trimester & & $*$ & & & $* *$ & & & & & & $*$ & \\
\hline & No. of children & & & & & & & & & & & $*$ & \\
\hline & History of abortion & & & & & & & & & & & & \\
\hline \multirow{6}{*}{ 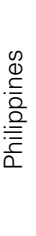 } & Age group & & & & & & & & & & & & \\
\hline & Marital status & & & & & & & & & & & & \\
\hline & Education & & $*$ & & & & & & & & & & \\
\hline & Trimester & & & & & & & & & & & & \\
\hline & No. of children & & & & & & & & & & $* *$ & & \\
\hline & History of abortion & & & & & & & & & & & & \\
\hline \multirow{6}{*}{$\begin{array}{l}\frac{\bar{C}}{\frac{\pi}{D}} \\
\frac{\bar{D}}{\bar{D}} \\
\stackrel{F}{F}\end{array}$} & Age group & & & & & & $*$ & $*$ & & $*$ & $* *$ & $*$ & $*$ \\
\hline & Marital status & & & & & $*$ & $* *$ & $* *$ & & & & $* *$ & $* *$ \\
\hline & Education & $*$ & $* *$ & $* *$ & $* *$ & $* *$ & $* *$ & $*$ & $* *$ & $* *$ & $* *$ & $* *$ & $* *$ \\
\hline & Trimester & $* *$ & & & $*$ & $* *$ & $*$ & $*$ & $* *$ & & $*$ & & $* *$ \\
\hline & No. of children & & & & & & & & & $* *$ & $* *$ & $*$ & \\
\hline & History of abortion & & & & $*$ & & & & & & & & \\
\hline
\end{tabular}

Significant association were tested by chi-square, ${ }^{*} p<0.05 ;{ }^{* *} p<0.01$. P1 to $P 7$ are the preventive knowledge on ways to avoid toxoplasmosis. P1: Feeding your

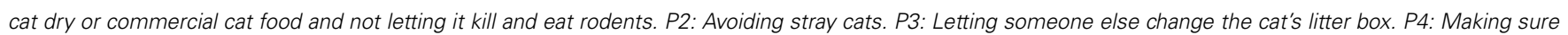

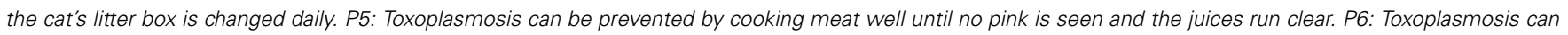

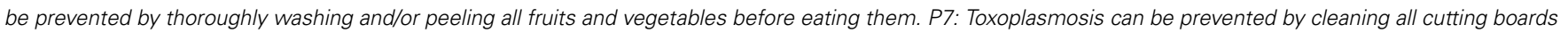

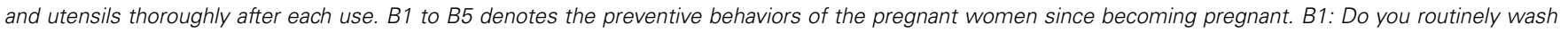

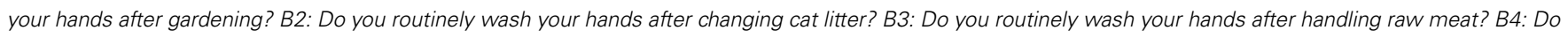
you routinely wash your hands before eating food? B5: Do you eat raw meat?

reported in this region. Our finding is supported by a previous study in Belgium showed that there was a significant decrease in the incidence of Toxoplasma seroconversion after the introduction of intensive counseling for pregnant women about toxoplasmosis (Gollub et al., 2008). Other previous studies also highlight the importance of health education among the pregnant women in order to reduce the seroprevalence of this disease hence minimizing the adverse effects of infection in the fetus or newborn (Fonseca et al., 2012; Amin et al., 2013; Pereboom et al., 2013). Unfortunately, it was found that some physicians, obstetrics, and medical staffs had lack of knowledge on this parasitic infection thus failed to provide sufficient information the pregnant women (Ziemba et al., 2010; Alvarado-Esquivel et al., 2011; da Silva et al., 2011). Therefore, medical personnel should be educated on the level of knowledge and practice of toxoplasmosis, subsequently, an appropriate health education could then be provided to pregnant women and the healthcare related staffs to better understand manifestation of this parasitic infection.

\section{CONCLUSIONS}

In this study, the knowledge and practices on toxoplasmosis among the pregnant women from Malaysia, Philippines, and Thailand were studied. Of the respondents, a substantial part did have knowledge about preventive practices to avoid toxoplasmosis during their pregnancy. Advising pregnant women about their healthy lifestyle and practices of good preventive measures to prevent this parasitic disease remain crucial. Awareness and education about this parasitic infection in pregnant woman would be helpful in preventing disease transmission and the incidence of clinical outcomes in their carried fetus or newborns. In accordance with this study, we have implemented healthcare education programme related to Toxoplasma infection in pregnant women by distribution of brochures in the study areas; Malaysia, Philippines and Thailand and in their respective national languages (Brochures included as Supplement 2).

\section{AUTHOR CONTRIBUTIONS}

Cristina C. Salibay, Nongyao Sawangjaroen, and Veeranoot Nissapatorn designed the study. Cristina C. Salibay, Julieta Z. Dungca, Mary Mae M. Cheung, Nongyao Sawangjaroen, and SiLay Khaing carried out the experiment, Hemah Andiappan contributed most on manuscript writing. Cristina C. Salibay, Hemah Andiappan, Nongyao Sawangjaroen, Veeranoot Nissapatorn, Waenurama Chemoh, and Ching Xiao Teng helped in manuscript writing and editing. Cristina C. Salibay, Julieta Z. Dungca, Mary Mae M. Cheung, Noor A. Mat Adenan, Nongyao Sawangjaroen, Si-Lay Khaing, Yee-Ling Lau and Veeranoot Nissapatorn provided opinions and suggestions about this manuscript. All authors read and approved the final version of the manuscript. 


\section{ACKNOWLEDGMENTS}

The authors would like to thank all the participated pregnant women for their consistent support and cooperation throughout this study. The authors thank the doctors, nurses, and staffs of the ANC at Department of Obstetrics and Gynecology, University of Malaya Medical Centre, Kuala Lumpur, Malaysia, at General hospitals Lying in/Private Clinics in Luzon and Mindanao, Philippines and at the Songklanagarind and Hatyai hospital, Songkhla province and Pattani hospital, Pattani province, Thailand for their assistances and contribution in this study. The authors also thank all the Head of Departments, and staffs directly or indirectly helped us in rendering technical supports. This study was supported by the University of Malaya High Impact Research Grant (UM-MOHE UM.C/625/1/HIR/MOHE/MED/18) from the Ministry of Higher Education, Malaysia, Post-graduates research grants (PV 049/2011B and PV 014/2012A) and University Malaya Research Grants (UMRG 544/14HTM).

\section{SUPPLEMENTARY MATERIAL}

The Supplementary Material for this article can be found online at: http://www.frontiersin.org/journal/10.3389/fmicb. 2014.00291/abstract

\section{REFERENCES}

Alvarado-Esquivel, C., Sifuentes-Álvarez, A., Estrada-Martínez, S., and RojasRivera, A. (2011). Knowledge and practices on toxoplasmosis in physicians attending pregnant women in Durango, Mexico. Gac. Med. Mex. 147, 311-324.

Amin, T. T., Ali, M. N., Alrashid, A. A., Al-Agnam, A. A., and Al Sultan, A. A. (2013). Toxoplasmosis preventive behavior and related knowledge among Saudi pregnant women: an exploratory study. Glob. J. Health Sci. 5, 131-143. doi: 10.5539/gjhs.v5n5p131

Bangoura, B., Zöller, B., Koethe, M., Ludewig, M., Pott, S., Fehlhaber, K., et al. (2013). Experimental Toxoplasma gondii oocyst infections in turkeys (Meleagris gallopavo). Vet. Parasitol. 196, 272-277. doi: 10.1016/j.vetpar.2013.03.032

Chintapalli, S., and Padmaja, I. J. (2013). Seroprevalence of toxoplasmosis in antenatal women with bad obstetric history. Trop. Parasitol. 3, 62-66. doi: 10.4103/2229-5070.113915

Chou, C. S., Lin, L. Y., Chen, K. M., and Lai, S. C. (2011). Flow cytomix analysis for Toxoplasma gondii infection in pregnant women in central Taiwan. J. Obstet. Gynaecol. 31, 375-379. doi: 10.3109/01443615.2011.568073

Costa, F. F., Gondim, A. P., Lima, M. B., Braga, J. U., Vieira, L. J., and Araújo, M. A. (2012). Preventive behavior for toxoplasmosis in pregnant adolescents in the state of Ceara, Brazil. BMC Public Health 12:73. doi: 10.1186/1471-2458-12-73

da Silva, L. B., de Oliveira Rde, V., da Silva, M. P., Bueno, W. F., Amendoeira, M. R., and de Souza Neves, E. (2011). Knowledge of toxoplasmosis among doctors and nurses who provide prenatal care in an endemic region. Infect. Dis. Obstet. Gynecol. 2011:750484. doi: 10.1155/2011/750484

Doudou, Y., Renaud, P., Coralie, L., Jacqueline, F., Hypolite, S., Hypolite, M., et al. (2014). Toxoplasmosis among pregnant women: high seroprevalence and risk factors in Kinshasa, Democratic Republic of Congo. Asian Pac. J. Trop. Biomed. 4, 69-74. doi: 10.1016/S2221-1691(14)60211-2

Elsheikha, H. M. (2008). Congenital toxoplasmosis: priorities for further health promotion action. Public Health 122, 335-353. doi: 10.1016/j.puhe.2007.08.009

Fakhfakh, N., Kallel, K., Ennigro, S., Kaouech, E., Belhadj, S., and Chaker, E. (2013). Risk factors for Toxoplasma gondii and immune status of pregnant women: cause and effect. Tunis. Med. 91, 188-190. Available online at: http://www.latunisiemedicale.com/article-medicale-tunisie.php?article $=2161 \&$ Codelang=en

Ferezin, R. I., Bertolini, D. A., and Demarchi, I. G. (2013). Prevalence of positive serology for HIV, hepatitis B, toxoplasmosis and rubella in pregnant women from the northwestern region of the state of Parana. Rev. Bras. Ginecol. Obstet. 35, 66-70. doi: 10.1590/S0100-72032013000200005

Fonseca, A. L., Silva, R. A., Fux, B., Madureira, A. P., Sousa, F. F., and Margonari, C. (2012). Epidemiologic aspects of toxoplasmosis and evaluation of its sero- prevalence in pregnant women. Rev. Soc. Bras. Med. Trop. 45, 357-364. doi: 10.1590/S0037-86822012000300015

Gollub, E. L., Leroy, V., Gilbert, R., Chêne, G., and Wallon, M. (2008). Effectiveness of health education on Toxoplasma-related knowledge, behavior, and risk of seroconversion in pregnancy. Eur. J. Obstet. Gynecol. Reprod. Biol. 136, 137-145. doi: 10.1016/j.ejogrb.2007.09.010

Halonen, S. K., and Weiss, L. M. (2013). Toxoplasmosis. Handb. Clin. Neurol. 114, 125-145. doi: 10.1016/B978-0-444-53490-3.00008-X

Hill, D. E., and Dubey, J. P. (2013). Toxoplasma gondii prevalence in farm animals in the United States. Int. J. Parasitol. 43, 107-113. doi: 10.1016/j.ijpara. 2012.09.012

Hua, H. Y., Tang, F., Liu, Y. X., You, L., Dong, M. H., Chen, Y. E., et al. (2013). Survey of Toxoplasma gondii infection among pregnant women in Jiangsu Province, China. Zhongguo Xue Xi Chong Bing Fang Zhi Za Zhi 25, 56-58, 79.

John, D. T., and Petri, W. A. (2006). Markell and Voge's Medical Parasitology, 9th Edn. St. Louis, MO: Elsevier Inc.

Jones, J. L., Folashade, O., Joni, S., Elizabeth, K., Lopez, A., Jay, S., et al. (2003). Toxoplasmosis-related knowledge and practices among pregnant women in the United States. Infect. Dis. Obstet. Gynecol. 11, 139-145. doi: 10.1080/10647440300025512

Kang, S. W., Doan, H. T., Noh, J. H., Choe, S. E., Yoo, M. S., Kim, Y. H., et al. (2013). Seroprevalence of Toxoplasma gondii and Trichinella spiralis infections in wild boars (Sus scrofa) in Korea. Parasitol. Int. 62, 583-585. doi: 10.1016/j.parint.2013.08.015

Lopes, A. P., Dubey, J. P., Neto, F., Rodrigues, A., Martins, T., Rodrigues, M., et al. (2013). Seroprevalence of Toxoplasma gondii infection in cattle, sheep, goats and pigs from the North of Portugal for human consumption. Vet. Parasitol. 193, 266-269. doi: 10.1016/j.vetpar.2012.12.001

Montoya, J. G., and Remington, J. S. (2008). Management of Toxoplasma gondii infection during pregnancy. Clin. Infect. Dis. 47, 554-556. doi: 10.1086/ 590149

Mwambe, B., Mshana, S. E., Kidenya, B. R., Massinde, A. N., Maziqo, H. D., Micheal, D., et al. (2013). Sero-prevalence and factors associated with Toxoplasma gondii infection among pregnant women attending antenatal care in Mwanza, Tanzania. Parasit. Vectors 6:222. doi: 10.1186/17563305-6-222

Nissapatorn, V., Noor Azmi, M. A., Cho, S. M., Fong, M. Y., Init, I., Rohela, M., et al. (2003). Toxoplasmosis: prevalence and risk factors. J. Obstet. Gynecol. 23, 618-624. doi: 10.1080/01443610310001604376

Nissapatorn, V., Suwanrath, C., Sawangjaroen, N., Ling, L. Y., and Chandeying, V. (2011). Toxoplasmosis-serological evidence and associated risk factors among pregnant women in southern Thailand. Am. J. Trop. Med. Hyg. 85, 243-247. doi: 10.4269/ajtmh.2010.10-0633

Paquet, C., and Yudin, M. H. (2013). Toxoplasmosis in pregnancy: prevention, screening, and treatment. J. Obstet. Gynaecol. Can. 35, 78-79.

Pereboom, M. T., Manniën, J., Spelten, E. R., Schellevis, F. G., and Hutton, E. K. (2013). Observational study to assess pregnant women's knowledge and behavior to prevent toxoplasmosis, listeriosis and cytomegalovirus. BMC Pregnancy Childbirth 13:98. doi: 10.1186/1471-2393-13-98

Pereira, K. S., Franco, R. M., and Leal, D. A. (2010). Transmission of toxoplasmosis (Toxoplasma gondii) by foods. Adv. Food Nutr. Res. 60, 1-19. doi: 10.1016/S10434526(10)60001-0

Sakikawa, M., Noda, S., Hanaoka, M., Nakayama, H., Hojo, S., Kakinoki, S., et al. (2012). Anti-Toxoplasma antibody prevalence, primary infection rate, and risk factors in a study of toxoplasmosis in 4,466 pregnant women in Japan. Clin. Vaccine Immunol. 19, 365-367. doi: 10.1128/CVI.05486-11

Salibay, C. C., Dungca, J. Z., and Claveria, F. G. (2008). Serological survey of Toxoplasma gondii infection among Urban (Manila) and Suburban (Dasmariñas, Cavite) Residents, Philippines. J. Protozool. Res. 18, 26-33. Available online at: http://ir.obihiro.ac.jp/dspace/handle/10322/1835

Torgerson, P. R., and Mastroiacovo, P. (2013). The global burden of congenital toxoplasmosis: a systematic review. Bull. World Health Organ. 91, 501-508. doi: 10.2471/BLT.12.111732

Torrey, E. F., and Yolken, R. H. (2013). Toxoplasma oocysts as a public health problem. Trends Parasitol. 29, 380-384. doi: 10.1016/j.pt.2013.06.001

Verma, R., and Khanna, P. (2013). Development of Toxoplasma gondii vaccine: a global challenge. Hum. Vaccin. Immunother. 9, 291-293. doi: 10.4161/hv. 22474 
Zemene, E., Yewhalaw, D., Abera, S., Belay, T., Samuel, A., and Zeynudin, A. (2012). Seroprevalence of Toxoplasma gondii and associated risk factors among pregnant women in Jimma town, Southwestern Ethiopia. BMC Infect. Dis. 12:337. doi: 10.1186/1471-2334-12-337

Ziemba, J., Nowakowska-Głab, A., Wilczyñski, J., Maniecka-Bryła, I., and Nowakowska, D. (2010). Knowledge of toxoplasmosis among pregnant women, midwifes, medical students and obstetricians. Med. Pr. 61, $271-276$.

Conflict of Interest Statement: The authors declare that the research was conducted in the absence of any commercial or financial relationships that could be construed as a potential conflict of interest.

Received: 20 March 2014; accepted: 26 May 2014; published online: 11 June 2014.
Citation: Andiappan H, Nissapatorn V, Sawangjaroen N, Khaing S-L, Salibay CC, Cheung MMM, Dungca JZ, Chemoh W, Xiao Teng C, Lau Y-L and Mat Adenan NA (2014) Knowledge and practice on Toxoplasma infection in pregnant women from Malaysia, Philippines, and Thailand. Front. Microbiol. 5:291. doi: 10.3389/fmicb. 2014.00291

This article was submitted to Microbial Immunology, a section of the journal Frontiers in Microbiology.

Copyright (c) 2014 Andiappan, Nissapatorn, Sawangjaroen, Khaing, Salibay, Cheung, Dungca, Chemoh, Xiao Teng, Lau and Mat Adenan. This is an open-access article distributed under the terms of the Creative Commons Attribution License (CC BY). The use, distribution or reproduction in other forums is permitted, provided the original author(s) or licensor are credited and that the original publication in this journal is cited, in accordance with accepted academic practice. No use, distribution or reproduction is permitted which does not comply with these terms. 